\section{La realidad de la práctica escolar y el deseo de interculturalidad. La enseñanza de quechua en colegios particulares en Cochabamba, Bolivia*}

\author{
Inge Sichra**
}

Resúmen: Este trabajo tiene como objetivo detectar en qué medida la enseñanza del quechua aporta a la interculturalización de alumnos castellano monolingües de dos colegios particulares que han incorporado la lengua indígena en su currículo. La premisa que sustenta la investigación establece que los procesos pedagógicos son producto de ideología y generan ideología. Para romper el ciclo de reproducción de la posiciones hegemónicas transmitidas como ideología, "las teorías críticas se proponen lograr que los 'agentes' tomen conciencia de la coerción oculta, y por ello, tratan de liberarles de dicha coerción y colocarles en una situación que les permita determinar en dónde residen sus verdaderos intereses" (Wodak 2003, p.34). Presentamos a continuación las opiniones de niños y padres de familia de colegios particulares respecto a la importancia del quechua en un contex to de conflictos sociales y las contrastamos con los referentes culturales que los niños reciben en el aula durante las clases de quechua. Las conclusiones apuntan, entre otras, a la sorprendente ideología progresista expresada por los padres de familia y alumnos que favorecería la interculturalización como efecto de la enseñanza de quechua en el colegio, en contraste con la práctica de aula. Esta práctica encasilla la lengua indígena en el mundo rural, la aísla en un mundo estático y alejado de toda actualidad, difundiendo a la vez prejuicios respecto a los hablantes y su cultura.

Palabras clave: cultura escolar; lengua indígena como asignatura escolar; interculturalidad en la educación.

Abstract: The aim of this study is to detect in what measure the teaching of Quéchua contributes to the interculturalization of monolingual Spanish speaking students in two private colleges which have incorporated the indigenous language into their curriculum. The premise that sustains the research establishes that the pedagogical processes are a product of ideology and generate ideology. In order to finish with the reproductive cycle of hegemonical standpoints transmitted as ideology, "the critical theories propose that the 'agents' become aware of the hidden coercion, and to accomplish this, mean to liberate them from this coercion and put them in a situation which permits them to determine where their real interests lie" (Wodak, 2003, p.34). Following this, the opinions of the
*Este trabajo es parte de una investigación más extensa realizada el 2004 como aporte a la línea de investigación Bilingüismo e interculturalidad en áreas urbanas del PROEIB Andes (Sichra 2006). Fue posible gracias a la disposición de los directores y las docentes de los colegios San Agustín

y CENDI de abrirme sus aulas sin contemplaciones, y a la generosidad de madres, padres y alumnos del 6to, $7 \mathrm{mo}$ y 8 vo curso del San Agustín y 6to de

CENDI de brindarme su tiempo y su interés.

** Asesora nacional del Programa de Formación en

Educación Intercultural

Bilingüe para los países andinos PROEIB Andes en la Universidad Mayor de San Simón, Cochabamba,

Bolivia. Coordina en este programa las maestrías en

Educación Intercultural Bilingüe y es docente del Area de lenguaje. isichra@proeibandes.org 
children and parents of private colleges are presented with respect to the importance of Quéchua in a context of social conflicts and these are contrasted with cultural references that the children receive during the Quéchua classes. The conclusions bring out, amongst others, the surprising progressive ideology expressed by the parents and pupils which favors interculturalization as an effect of teaching Quéchua in the college, in contrast with classroom practice. This practice limits the indigenous language to the rural world, isolates it in a static world away from the present, spreading at the same time biases respecting the speakers and their culture.

Key words: school culture; indigenous language as a school discipline; crosscultural education.

\section{Introduccion}

Como en todos los países latinoamericanos, los procesos socioeconómicos también producen en Bolivia una creciente migración interna y expulsión de la población rural hacia asentamientos urbanos. Siguiendo la tendencia mundial, la población boliviana ${ }^{1}$ se concentra mayoritariamente (62\%) en áreas urbanas. Distingue a Bolivia el hecho de que $39.7 \%$ de la población mayor de 15 años a nivel nacional se haya identificado en el último censo de 2001 con un pueblo indígena de los 36 que habitan en el país (PROEIB Andes, 2005). Los datos de adscripción étnica se refieren a los pueblos quechua (49\%) y aimara (41\%), así como a pueblos de tierras bajas como chiquitano (3.6\%), guaraní (2.5\%), moxeño $(1.4 \%)$ (ibid). Es necesario destacar que esta adhesión fue expresada en todos los casos mayoritariamente por pobladores de zonas urbanas.

Una respuesta de la población citadina a las migraciones internas en Bolivia es su paulatino y creciente proceso de interculturalización y/ o bilingüización. Como único país en Latinoamérica, Bolivia registra en el último censo de 2001 un porcentaje relativamente similar de hablantes monolingües en castellano (46.8 \%) al porcentaje de hablantes bilingües lenguas indígenas y castellano (40.8 \%). Algo más de un décimo de la población es monolingüe en lenguas originarias. Si nos atenemos al último censo para obtener una impresión del bilingüismo urbano, en Cochabamba, $54 \%$ de la población urbana se declaró bilingüe, en La Paz 48\%, en Santa Cruz un quinto de la población urbana es bilingüe (INE 2002).

Los fenómenos mencionados se inscriben, a nuestro entender, en un momento histórico de reconocimiento de una dinámica social de índole conflictiva que desafía a la minoría criolla/mestiza que hegemonizó el poder en el país ${ }^{2}$. Los movimientos sociales en Bolivia han cuestionado la configuración sociopolítica del país, lo cual ha provocado, a su vez, 
reacciones contrarias a la noción de interculturalidad en los sectores que ven cuestionada su posición hegemónica y excluyente. Con movilizaciones y levantamientos en todo el país, las organizaciones indígenas y campesinas han sido protagonistas fundamentales de los cambios en Bolivia en los últimos cinco años, logrando rescisiones de contratos con empresas transnacionales, la renuncia de dos presidentes e imponiendo una agenda política de refundación del país con la elección de Evo Morales como presidente. "La otra Bolivia" con la que se ven confrontados sectores dominantes criollo/mestizos está generando amplias discusiones y reflexiones en espacios políticos sobre la conformación nacional y la identidad ciudadana. A la conclusión de tres semanas de convulsiones sociales que provocaron la renuncia del Presidente Mesa en junio de 2005, varios analistas sostienen que "lo que ha explotado en este momento es aquello que estaba escondido, callado y silenciado: el mundo indígena, que siempre ha estado subalternizado", como lo formula Ana María Romero de Campero (2005, p.5), exdefensora del Pueblo.

El contexto de nuevas tensiones y dinámicas sociales exige del Estado la generación y aplicación de políticas educativas y lingüísticas. La atención de la interculturalidad en la población no indígena en el ámbito educativo, tanto en el sector público como privado, cobra gran relevancia en Bolivia a partir de los profundos cambios políticos propiciados por el gobierno de Evo Morales. Así por ejemplo, el proyecto de la Nueva ley de la educación boliviana establece en el artículo 1 (Bases, fines y objetivos de la educación boliviana) que el sistema educativo es intracultural, intercultural y plurilingüe porque " promueve la interrelación y convivencia en igualdad de oportunidades a través de la valoración y respeto recíproco entre las culturas del Estado Plurinacional y del mundo". El artículo 2 (Fines de la educación boliviana) establece, por su parte, "desarrollar la intraculturalidad, interculturalidad y plurilingüismo para la realización plena e íntegra del ser humano y la conformación de una sociedad armónica" (MECs 2006).

Hace más de una década, con los cambios a la Constitución Política del Estado en 1993 y la implantación de la Reforma Educativa con sus ejes de interculturalidad y participación social en 1994, en Bolivia se iniciaron transformaciones en el ámbito educativo de esta "sociedad absoluta y profundamente incomunicada" (Ana María Romero de Campero 2005, p.5). En cuanto a la inclusión de las lenguas indígenas en el currículo de establecimientos que congregan a alumnos castellano hablantes, es paradójicamente en los colegios particulares donde mucho antes de la Reforma se dieron las primeras experiencias de asignaturas en quechua 
o aimara. Albó y Romero (2004, p.62) califican de progresistas estos colegios privados que consideraron la apertura a la diversidad lingüística boliviana como una formación cívica "mucho más eficaz que largas disquisiciones teóricas sobre la estructura del Estado" ${ }^{3}$. Desde esta perspectiva, una asignatura de quechua en un colegio particular con alumnos castellano hablantes adquiere importancia más allá de las exigencias propias del sistema educativo. Como ninguna asignatura, la clase de quechua tendría el potencial de remitir a develar críticamente una realidad indígena históricamente negada o reducida a lo rural que movimientos sociales se encargan con toda fuerza de cuestionar. La lengua indígena cobra un significado educativo a raíz de su visibilización y el impacto político de sus hablantes en Bolivia. Nos interesa, por lo tanto, rastrear el aporte de estos avances de política educativa en la interculturalización de alumnos de sectores criollo/mestizos hegemónicos en la ciudad de Cochabamba ${ }^{4}$.

Después de mencionar algunos referentes conceptuales como base para el análisis, revisamos la práctica educativa de dos establecimientos educativos particulares de Cochabamba ${ }^{5}$ a partir de observaciones de aula y conversaciones con las profesoras encargadas de la asignatura de quechua en ambos colegios y la contrastamos con las opiniones de padres y madres de familia respecto al sentido y valor de la enseñanza de quechua a sus hijos.

\section{Referentes conceptuales}

\section{Interculturalidad}

La introducción de la noción de interculturalidad en la discusión académica y política en Latinoamérica ha estado fuertemente marcada por la problemática educativa. La institución escuela fue - y sigue siendo en gran medida - expresión de una relación de dominación de una cultura a otra(s) "mediante las agencias de control que reproducen las formas dominadoras...lo que significa la irrupción brusca en el sistema simbólico de la otra cultura y en sus formas de producción material" (Bodnar y Rodríguez, 1993, p.33). Estamos frente al reconocimiento de relaciones interétnicas asimétricas entre una cultura y una lengua hegemónica y unas lenguas y culturas subordinadas que se fundan sobre una doble situación de opresión (GIGANTE et al., 1986, p.7): la explotación económica y la discriminación racial, cultural, lingüística. Rescatamos un aspecto central en la noción interculturalidad que apunta a una definición propositiva 
más que descriptiva del término: "Cuando hablamos de interculturalidad nos referimos a que es necesario examinar en cada momento cómo han sido históricamente las relaciones de poder" (Bodnar y Rodríguez, 1993, p.35). Desde esta posición, la comprensión de interculturalidad no puede hacer caso omiso de las relaciones de poder desiguales, históricamente planteadas entre unas culturas consideradas como inferiores y otras como superiores. De esta manera, la interculturalidad como proyecto político y postura individual permitiría la ampliación del sistema simbólico y maneras enriquecidas de transformar el mundo al centrarse "en el establecimiento $\mathrm{y}$ fortalecimiento de relaciones humanas basadas en el respeto y el reconocimiento de las diferencias" (op.cit. 35).

La interculturalidad desde la perspectiva de los no-indígenas no ha recibido aún tanta atención en Latinoamérica como aquella desde la perspectiva de los indígenas. Con una connotación distinta, aunque igualmente buscando superar el etnocentrismo, el concepto ha sido introducido tímidamente en el currículo del sistema educativo de algunos países europeos que reconocen más y más a sus minorías y migrantes ${ }^{6}$, tanto de los antiguos miembros de la Unión Europea (España, Alemania, Holanda) como también de los recientes (Austria) y de nuevos países surgidos de la ex Yugoslavia (Slovenia). Empiezan a haber varios estudios sobre estos cambios que buscan entender por qué,

aunque hoy en día prácticamente todos los Estados-naciones partícipes en este debate postulan practicar alguna variante de educación intercultural, el análisis de los discursos generados por los actores institucionales demuestra que la escuela sigue resistiéndose exitosamente a su interculturalización (Dietz 2003, p.166)

Interculturalidad en la educación

Para avanzar en una "etnografía de lo intercultural" hará falta combinar tres niveles en tal investigación: el plano discursivo institucional, su concreción en las didácticas y los diseños curriculares y, por último, la práctica escolar áulica misma (Dietz, 2003, p.157-158),

Es en este nivel de la práctica escolar donde se concreta la 'interculturalidad en el aula' (Albó y Romero, 2004; Walsh, 2001). Los aspectos relevantes en este nivel van desde procedimientos y metodologías utilizados en el aula, pasando por el fomento de habilidades sociales hasta la educación en valores.

Algunos autores como Perrenoud (1984) y Hutmacher (2001) llaman al tercer nivel de práctica escolar áulica 'currículo real' - lo que los alumnos realmente aprenden en la escuela, no lo que está previsto o 
debe ser enseñado -, en el cual distinguen, por un lado, las relaciones y, por otro, la definición, selección e interpretación de conocimiento escolar. Abordar estos aspectos, sin embargo, requiere de la ayuda del concepto de 'currículo oculto' del proceso educativo. Para Iván Illich (1970, p.3233), el currículo oculto es transmitido de manera inconsciente y consciente a diario por los maestros en el aula y por la institución educativa y permean la educación en su conjunto.

Even the best of teachers cannot entirely protect his pupils from it. Inevitably, this hidden curriculum of schooling adds prejudice and guilt to the discrimination which a society practices against some of its members and compounds the privilege of others with a new title to condescend to the majority ${ }^{7}$.

El currículo oculto puede ser entendido como un mecanismo de socialización escolar por el cual se aprenden los roles sociales preferidos por la sociedad, a ser subordinados y a subordinar a otros, se adquiere una manera particular de ver el mundo. Lo establecido en documentos escolares no sería lo más importante para el aprendizaje en la escuela, sino el aspecto de lo no explicitado: la organización de la enseñanza, los rituales, las relaciones interpersonales, los procedimientos de evaluación, etc. Es a este nivel que se generan los objetivos no-intencionales de la transmisión de creencias y valores de la sociedad, hecho que responde a procedimientos de ocultamiento de las disonancias, discrepancias y conflictos entre principios sociales y organización social que todas las sociedades tienen ante sus miembros (op.cit, p.51).

Hutmacher (2001, p.17) aclara que no hay nada 'oculto' en esta parte del currículo, al contrario, todos lo conocen porque han pasado por esa experiencia en la escuela. Se trata más bien de ignorar, no ocultar, estos aspectos de la experiencia escolar de los niños y jóvenes debido a la ceguera que la familiaridad de años y años de permanencia en la escuela provoca.

\section{Metodologia}

El estudio se define como etnográfico en la medida que pueda "desmontar los elementos políticos, ideológicos y alienantes que intervienen en las concepciones, usos y prácticas de los protagonistas y saber distinguir el sentido émico que caracteriza sus inscripciones del sentido ético y político de sus interpretaciones" (Bertely, 2000).

Me contacté con padres y madres de los colegios particulares San Agustín (SA) ${ }^{8}$ y $\mathrm{CENDI}^{9}$ en Cochabamba. Para ello recurrí al sistema

bola de nieve, empezando por algunos conocidos míos que accedían a 
entrevistarse y que me daban nombres de otras personas eventualmente dispuestas a conversar conmigo. Puedo decir que a todos les sorprendió mi interés en el tema, aunque la mayoría dijo haberse preocupado de una $\mathrm{u}$ otra forma del asunto a raíz de las tareas y calificaciones de los hijos en la asignatura de quechua.

Accedí a los alumnos a través de los padres, que permitieron las entrevistas el mismo día que los visitaba en sus casas o en otros días. Aunque con cierta timidez inicial, ninguno se negó a que grabara la conversación. Sin embargo, en muchas ocasiones no se desarrolló una conversación y se generó solamente un diálogo de pregunta-respuesta. En varios casos se trató de conversaciones con hermanos o amigos.

Para ingresar a los dos colegios particulares investigados, los respectivos directores me dieron los horarios de los cursos que me interesaban visitar y se comunicaron con los docentes. De esta forma, en un ambiente bastante distendido, pude observar las clases entre abril y junio 2004.

El currículo real

Cuando le expliqué a la profesora del colegio SA que me interesa entrar a observar clases para ver cómo los alumnos comprenden la cultura quechua, ella dejó en claro que cultura se trata en ciencias sociales, ella no lo hace en su clase. "Yo enseño quechua en castellano". Nos preguntamos entonces ¿Qué imagen promueve la profesora del quechua y de los quechua hablantes en alumnos castellano monolingües de colegios particulares? Cuáles son los referentes culturales de este 'objeto de estudio' que la profesora enseña?

Las fotos motivadoras de producción oral que la profesora del colegio SA utiliza son escenas de la cancha (venta de rosquetes, venta de cosas usadas), personas con vestimentas típicas (tocando charango, sentadas en un parque), vistas de paisajes rurales. El vocabulario básico para los ejemplos que se utilizan en la explicación gramatical del texto fotocopiado y oralmente en clase está referido generalmente a la vida rural y es coherente con la identidad rural que se le asigna al hablante quechua. Con excepción de verbos cotidianos como dormir, hablar, salir, vivir, sentarse, ayudar, llorar, poder, vencer, haber, morir, dormir, llegar, reir, estar triste, se puede ver en las transcripciones de clases que el vocabulario básico se refiere a la naturaleza (cerro, río, piedra, flores, árbol, pescado, víbora); acciones o actividades propias de ambientes abiertos (correr, caminar, cazar, ladrar, subir); ámbitos de recreación (bailar, cantar, comer y tomar, comer charque); ámbito doméstico o de relevancia doméstica (comprar, lavar, cocinar, barrer, verter agua, sacar 
agua de pozo, moler en batán, animales domésticos, olla, cortar carne, lawa); ámbito agrícola (pelar maíz, choclo, papa, chuño, sembrar, regar, trabajar, amarrar vaca o caballo, elaborar chicha, llevar comida).

El cuento que se lee en clase también está ubicado en el ambiente rural. El mundo quechua para los alumnos en el colegio SA es rural. En el ejemplo que sigue, podemos ver cómo la profesora presenta el cuento a través de la lectura, induce a la traducción parte por parte para lograr la comprensión del cuento y, finalmente, asigna como tarea la traducción escrita del cuento.

\subsection{S.A. 7C, 5-7}

P: sigan la lectura con su texto. Ahí dice Juancito mayupi. Vamos a ver las travesuras de Juancito. ...

Uj kuti rirqani t'ajsaq mayuman. Dice mamay ...rikurqayku rumipatapi uj jamp'atituta. Hermanuyta jap'irqa chay jamp'atituta. Chantaqa ....

Mask'arqayku chay jamp'atituta churanaykupaq...bolsitaman... t'ajsay tukuytawan ripurqayku wasiman. Chayaytawan jap'irqayku ...chay jamp'atituta...wijch'urqayku ima. Tatay chanta maqawarqayku. Ahora aquí voy a leer de corrido. Concéntrense y vayan corrigiendo. Dice Uj kuti rirqani taqsaq mayuman. Mamay tajsasajtin rikhurqayku rumipatapi uj jamp'atituta. Hermanuyta jap'irqa chay jamp'atituta. Chantaqa mask'arqayku chay jamp'atituta churanaykupaq bolsitaman...

P: A ver, qué querrá decir. Hay verbos que hemos aprendido hoy.

A: Han ido al río con su mamá a lavar ropa

P: a ver por acá

A: a lavar, había un sapo

P: había un sapito, cuando hay ito ita es diminutivo. Qué más? hay algo más!

A: lo quería atrapar su hermano

P: qué más? Ya, lo llevó a su casa

A: en una bolsita

P: en una bolsita, qué pasó después?

A: tukuytawan?

P: lo cortaron, muy bien

A: el papá

P: el papá qué?

A...

P: oh, se lo comió? Hizo eso?

A: nooo

P: ahh entonces, a ver, qué hizo el papá? Los pegó

A: lo vió en la casa.

P: otra vez voy a volver a leer, concéntrense bien

Lee otra vez lentamente. . 
La escena es reproducida por los niños progresivamente. Podemos ver (líneas subrayadas) que la imaginación vuela en las partes que más oportunidades dan para añadir imágenes más fantásticas al cuento. Se puede pensar que es una estrategia para "acercar" la realidad del cuento ubicado en un contexto alejado, rural, a la cotidianeidad de los niños urbanos. Efectivamente, la traducción, es decir, el permanente recurso al castellano juega un rol central. Quizás no es exagerado pensar que el quechua en la clase no sólo se sostiene sino se conceptualiza a partir del castellano.

Otra faceta notoria de esta ruralidad del quechua es la recreación del ambiente propio de chichería y de su efecto, el estar borracho, que se produce en la generación de oraciones o diálogos en clase y resulta amenizar el evento. Ejemplos se dieron en la misma clase el mismo día, en cuatro momentos:

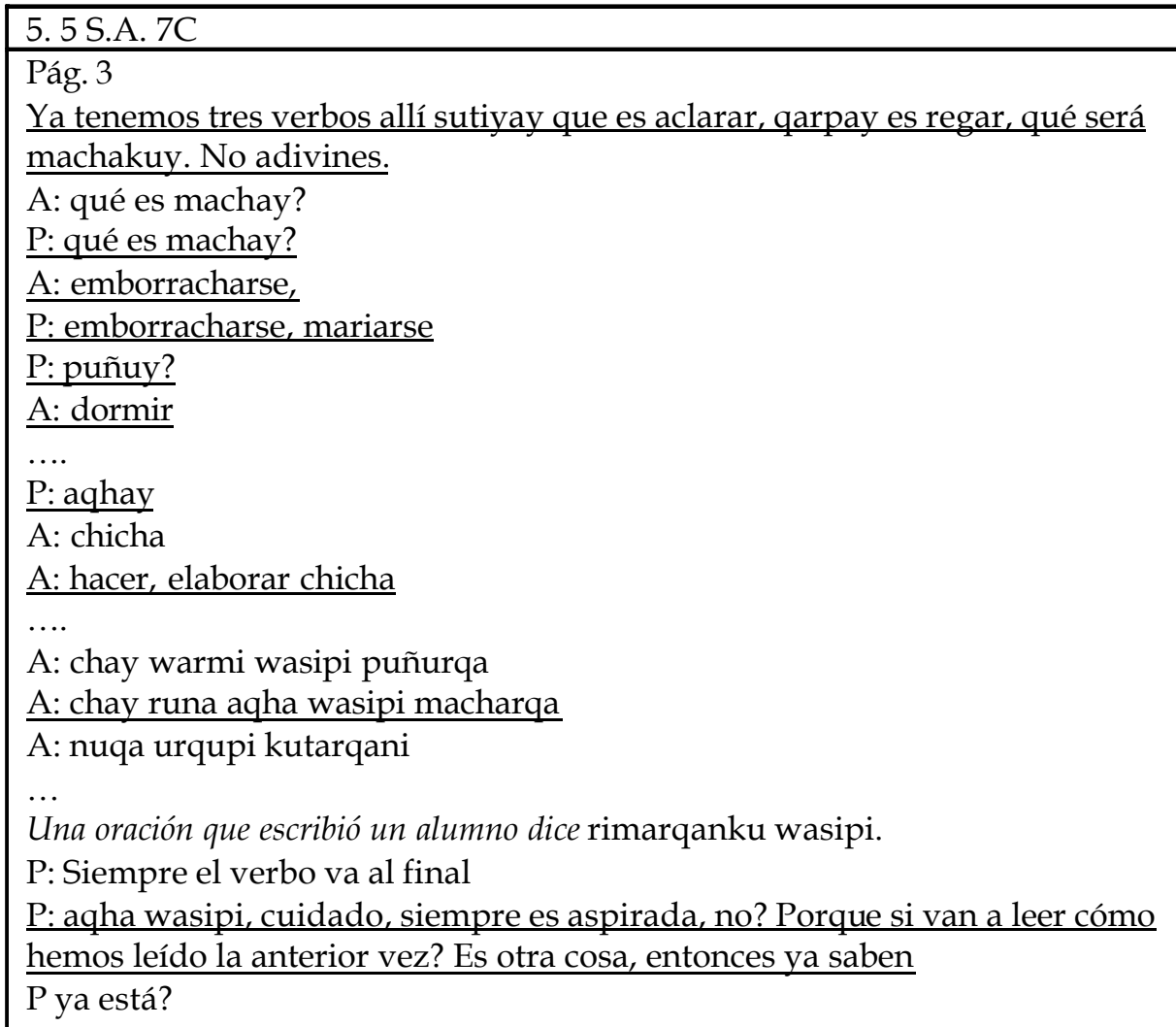


En la entrevista el 16.4.04, la profesora comenta que, a diferencia de los materiales didácticos para la enseñanza del inglés, para el quechua no hay modelos que los niños podrían imitar. En los materiales de inglés "hay casettes con artistas que los chicos imitan como modelos. Sería muy bueno tener algo así en quechua, pero no hay eso... En inglés los chicos se esmeran, tienen modelos. En quechua imitamos a los borrachitos, siempre surgen diálogos de chichería". A falta de modelos, se recrean situaciones que llaman la atención a los alumnos por su connotación tomar alcohol es algo prohibido y, por lo tanto, interesante para adolescentes. La denotación altamente negativa - la chicha se toma de forma consuetudinaria hasta emborracharse entre los quechuas - es minimizada por la profesora en su utilización del diminutivo, cosa que también hacen los alumnos:

I: por qué te gusta las oraciones con el "aqha wasi"?

Claudio: Porque es de los borrachitos, en el aqha wasi se habla de un borrachito, pienso en.... es chistoso. A nosotros dos nos parece super chistoso lo del aqha wasi, cuando están en la chichería, como hay en el diálogo, las cosas más o menos, así medio loquitos, de los borrachitos..... digamos. A mí y a mi amigo nos fascina lo del “aqha wasi".

En nuestro diálogo había una parte que era... "Yaw, imaynalla, kani machasqa", y yo le decía "nuqapis machasqa", y el otro decía "mashkata ukyankichiq", el otro decía "pachaq", y el otro decía "nuqa juno...... tanto, era un millón, y así, "kunan", mi amigo dice "maqay munankichu", y el otro decía "ari". Así era, en el diccionario habían estas palabras (Claudio SA 6to 10.6.04).

El alumno explica en la primera parte sobre la fascinación (y pena) que le provocan los personajes de la chichería, quizás por su existencia marginal, difícil de explicar o comprender. En la segunda parte "contextualiza" el diálogo poniéndose en los zapatos de los personajes y recreando la situación con elementos nuevos y probablemente no tan alejados de su vivencia personal, como ser el desafío a la pelea.

A la recurrente ruralidad y encierro de la lengua al espacio de la chichería se añade la característica deficitaria de la lengua y de sus hablantes. En el siguiente ejemplo, mientras los niños ejercitan un diálogo básico de saludo y presentación mutua, la profesora explica la refonetización quechua en el nombre "Francisco". 
5.5.S.A. $6 \mathrm{~A}, 4-5$

La profesora está leyendo el diálogo del texto fotocopiado.

P: Ahora la pregunta: ima sutiyki?

A: cuál es tu nombre?

P: sutiy Rancisco

A: mi nombre es Francisco.

P: qué será el nombre actual?

A: Francisco

P: Francisco, porque la f no existe, por eso es que tienen muchos problemas los del campo, porque pronuncian en su idioma. No es porque están cambiando el nombre, sino porque pronuncian en su idioma. No existe la $\mathrm{f}$. La f lo dicen como la $r$, eso tienen que tomar en cuenta. Hemos analizado en el alfabeto, se acuerdan, qué letras del alfabeto no se pueden tomar en cuenta. Por eso dice Rancisco. A ver, tú qué te llamas?

A: Sutiy Esteban.

P: Esteban, todavía, pero la b ya estuviera cambiado, no? Istiwan

A: risas

P: pero así la gente en su idioma pronuncia de esa forma

A: istiwan

P: ...estamos diciendo solamente la pronunciación que utiliza la gente del campo, no?

P: a ver Mauricio, cuál cambiarías? Mauricio es Mauricio nada más

A: no, Mauriciu

P: ya, Mauriciu, con la u. Muy bien. Estamos solamente copiando lo que la

gente en lugares lejanos pronuncian su idioma.

La declarada ausencia de elementos fonológicos existentes en el castellano crearía problemas a los hablantes del quechua cuando hablan castellano, "pronuncian en su idioma". Si bien la profesora resalta inicialmente algunas de las consonantes del castellano que no existen en el quechua, se concentra más y más en las vocales e y o. Conforme avanzan en el ejercicio de refonetización de nombres, se ridiculiza a los quechua hablantes a partir del "déficit" de su alfabeto.

Más allá de que el ambiente jocoso se provoca creando o recreando un imaginario de hablante quechua digno de burla, llama la atención que los fenómenos de la lengua - vistos desde el castellano y en consecuencia deficitarios - son abordados por la profesora focalizando en los hablantes. Abundan las referencias a que 'la gente pronuncia así en su idioma' en vez de mencionar la lengua como tal. Es en estos eventos nada neutros, cargados de sutiles prejuicios que se establece una ecuación Lengua Quechua = Hablantes Quechuas. Usualmente en las clases se gramaticaliza al máximo la lengua, se la vuelve objeto de estudio o 
instrumento simbólico, se habla sobre ella como si estuviera desprovista de actualidad, de hablantes, de contexto real y cotidiano, como si fuera una lengua muerta. Aquí es evidente una diferenciación de la profesora entre ellos, 'la gente', 'los del campo', 'los de lugares lejanos', 'los que pronuncian asi' $y$, por default, nosotros. Los que hablan quechua son los otros.

Un niño de octavo curso recuerda el primer año de quechua en el colegio cuando esta refonetización servía de diversión porque se recreaba el estereotipo campesino:

Ciro: No sé, al comienzo me parecía un poco chistoso, en vano, pero después me pareció interesante aprender un nuevo idioma y así, pero más que todo, nos hacíamos la burla de pasar quechua, mis compañeros y yo hacíamos chistes. Como si fuéramos campesinos, así...

I: Y qué decían?

Ciro: No sé, poníamos un acento medio del campo y solo charlábamos y eso nos hacía reír (Ciro SA 8vo 13.6.04)

Resumiendo lo observado en aula, podemos afirmar que la lengua indígena es tratada como un objeto de estudio cuyos referentes son la ruralidad y estereotipos creados por la carencia, el aislamiento geográfico y la distancia social. No aparece la funcionalidad comunicativa de la lengua indígena en el área urbana. El contexto sociolingüístico (bilingüismo social, presencia de lengua indígena la ciudad, quechuañol) no es recuperado en aula, mas bien se evidencia una pedagogía de lengua extranjera marcada por la ausencia de estímulo de aprendizaje. Es evidente la ausencia de motivación para aprender una lengua indígena. No se dan señales de proveer la asignatura de suficientes alicientes para crear actitudes positivas hacia el rescate y valorización del quechua como individuo, pueblo, cultura y lengua.

Se puede intuir cómo se establece un currículo oculto que marca con claridad la diferencia entre los unos y los otros y no deja duda sobre la identidad, el prestigio, la posición de los unos y de los otros con la consecuente asimetría social y desigualdad entre ellos. El currículo real develado en las observaciones difícilmente contribuye a favorecer la actitud positiva de los alumnos hacia los indígenas y hablantes de lengua indígena. Saville-Troike ${ }^{10}$ citada en Crawford \& Cadenas (2003, p.232) sostiene que "la existencia de estereotipos negativos con respecto a la cultura de la segunda lengua podría afectar negativamente los esfuerzos del grupo que aprende dicha lengua". Nuestro caso no estaría lejos de este efecto contraproducente de enseñar una lengua con modelos y contenidos desmotivadores. 
Según Velasco y otros (1993, p.319), esto tendría que ver con las paradojas inherentes a la institución educativa como tal:

Con el propósito manifiesto de erigirse en dispositivo universal de socialización, la escuela ha de reconocerse también en la encrucijada de responder a las formas de construir la realidad de las culturas particulares en las que pretende implantarse.

En el caso de esta investigación, no se aprovecha la escasa oportunidad que ofrecen tres años de instrucción con algunas horas semanales para que alumnos en la edad óptima de adquisición de lengua como son los sujetos aquí investigados se apropien de y se vislumbren con el quechua. Probablemente bastaría con preguntar a los niños, mejores conocedores de sus necesidades, intereses y oportunidades en aula. Como lo dijo tan acertadamente un alumno del 7mo grado del colegio SA: "Sí, porque la cosa cambia, en un momento en que algo te divierte y te interesa ahí aprendes no? Si una cosa no te interesa, no vas a aprender nunca".

Ante este panorama, nos preguntamos cuál es la experiencia de los niños con la lengua fuera de la escuela, cuál podría ser el atractivo para aprender la lengua. Alumnos, padres y madres de familia encuentran múltiples razones para ello, como veremos en la segunda parte. El amplio espectro de argumentos que ellos mismos presentan tiene un punto de convergencia: la unánime preferencia de los padres y madres de familia por que sus hijos tengan una asignatura quechua. Las razones van desde encarar el conflicto étnico en la sociedad hasta superar la incomunicación y distancia inherente a la diversidad lingüística y la utilidad profesional que el dominio de la lengua indígena supone.

\section{Opiniones sobre el mantenimiento de la asignatura de Quechua}

\section{Razones políticas}

En el plano familiar de los niños de los colegios investigados, se estaría reflejando el conflicto social boliviano a través de las adhesiones y simpatías de los miembros de la familia por uno u otro sector de la sociedad, motivo suficiente para pensar que la escuela debería propiciar la reflexión.

Y ahora más, en este tiempo en que este problema étnico ha resurgido tanto, no es cierto? Y que hay una polarización uno poco entre k'aras y no k'aras y todo esto, que también se debe dar al interior de algunas familias, entonces, cómo percibirán los chicos esto, yo creo que es importante analizar y ver no? (Petra 23.6.04) 
Enfrentarse al mundo que los rodea empezando por su reconocimiento y la percepción de su diversidad es lo que esta madre de familia aduce como razón de la exposición al quechua en el colegio.

Espero que (el quechua) por lo menos les ubique de que hay otro contexto, que hay otra gente, porque hay otros colegios donde no se habla, y están completamente abstraídos de lo que pueda significar, por decirte, una piedra más, un árbol más en el camino, u otra gente no? Solamente uno se percata o pueden percatarse de la existencia de otra diversidad de gente cuando los fastidia el caso concreto ...... el micrero, trufista, taxista (Marité 2.6.04).

Pasando del plano cotidiano al plano ideológico, en el siguiente testimonio, René, sociólogo, ve en la enseñanza del quechua una preparación de los jóvenes para aportar a los cambios de la sociedad. Su postura tiene que ver con el fracaso social de su generación y la expectativa de que la nueva generación encarará las tareas y compromisos postergados

René: Lo que yo creo es que tiene que volverse imprescindible. Yo personalmente creo que es una obligación, o sea obligar a que le metan quechua, aunque comencemos cruzados, o mezclados......

I: ¿En colegios?

René: En los colegios. Y ahora en estos tiempos, en esta afectación cultural y política y al mismo tiempo fuerzas que te obligan, que hacen surgir las cosas de abajo, es necesario que haya máximo de elementos. Somos la generación puente, la generación fracasada en todo, nunca hemos hecho una revolución, nunca hemos aprendido quechua, nunca hemos hecho nada, la hemos pasado divirtiéndonos, hemos hecho golpes queriendo construir algo. Con algo habrá que salir...

Desde una perspectiva menos ideológica pero referido también a una construcción de la sociedad boliviana que acepte como fundamento la convivencia, supere la discriminación racial y perciba la riqueza de la diversidad, Pepe, ingeniero civil, ve la conveniencia de la enseñanza de la lengua indígena como un aporte a la comprensión del otro.

Ahora que estamos en la lucha entre q'aras y t'aras, yo digo en todos los ambientes donde estoy, yo estoy en Bolivia y soy q'ara y me voy a quedar en Bolivia y no tengo que pensar de que los países tienen que ser en base a color ni raza ....Creo en la diversidad y creo en la convivencia, manteniendo costumbres y manteniendo todas esas características, o sea que dentro de ese punto de vista, me parece que el quechua debe enseñarse y debe profundizarse la investigación, en esa perspectiva de que el lenguaje modela la percepción (Pepe 1.6.04).

El encargo al colegio es explícito, bastando la enseñanza de lengua indígena para propiciar el conocimiento de su cultura: 
En una situación como la que tenemos ahora en el país que se están afirmando digamos las otras, como llamarlas, las otras etnias o grupos lingüísticos y creo que hay buena razón también de considerar que son grupos existentes con su propia cultura, con su propio idioma no? Y tratar de crear una mayor comprensión o un nexo entre las diferentes culturas investigando aunque sea a nivel muy básico por lo menos otro tipo de expresión. Porque yo no veo digamos el idioma desconectado del contenido cultural (Ana 3.6.05).

Este encargo a la enseñanza del quechua resulta utópico para Sandra, antropóloga, si no hay otras asignaturas que apoyan la formación humana y política en su sentido más amplio.

Por sí mismo, la enseñanza del quechua no puede provocar la comprensión de las relaciones sociales. Tendría que estar acompañado por otras materias como ciencias sociales, religión. En mis sobrinos no causó ningún efecto la enseñanza del quechua. Tampoco le dan el uso, está muy desligado, como una cosa exótica (Sandra 3.6.04).

Ariana tampoco percibe un efecto "comunicante" entre las culturas occidental e indígena con la enseñanza del quechua dada la distancia social, dejando en claro, sin embargo, que no se trata de claudicar y suprimir la enseñanza de la lengua.

Yo pienso que los dos mundos están tan cortados que no tiene un gran impacto a pesar de que estoy cien por ciento a favor que sigan esto, que enseñen quechua para que haya un acercamiento pero en mis hijos no he visto, no había un gran impacto, un gran interés en la cultura quechua, no tienen (Ariana 3.6.04).

Distancia social expresada como diferencia de clases es la explicación de Petra, econometrista, para el reducido interés de su hija por el quechua.

No veo resultados, mira mi hija es el segundo año que lleva quechua, no le veo un interés muy grande en el aprendizaje del quechua no? Me da la impresión de que ese mismo entorno, la clase social que esta ahí, tal vez no mira con aprecio el idioma quechua porque no considera que sea de su clase, no es cierto? (Petra 23.6)

Otros padres también observan actitudes de indiferencia de sus hijos aunque no adelantan alguna explicación que tenga que ver con su origen social y el contexto social del colegio. Hay, no obstante, otras razones para favorecer la asignatura del quechua en los colegios. 
Razón patriótica: Sentido de identidad nacional

En el testimonio siguiente, Ramiro también lamenta el desinterés de sus hijas por el quechua. De manera muy explícita, considera que el aprendizaje de la lengua puede ser un instrumento para recuperar la conciencia del valor histórico de lo nativo:

Ramiro: Lastimosamente no hay digamos esa predisposición de los chicos, de querer aprender el quechua, ojalá estuvieran predispuestos a aprender su idioma nativo, se les debe inculcar un poco esa importancia de saber un poco ...

I: Ustedes lo inculcan? ¿Quién les inculca?

Ramiro: Intentamos, sí, nosotros intentamos inculcarles...A mí me encantaría que fueran quechuistas, que hablaran. Entonces ojalá pudieran hablar en quechua, ojalá pudieran conocer a su cultura, a

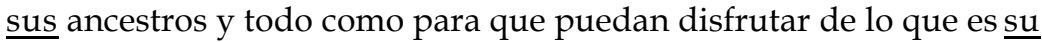
historia no?

Además de la formación histórica propiamente dicha, con el quechua se llegaría a generar una conciencia identitaria "colectiva". Ante el fraccionamiento político presentado en el argumento anterior, el quechua como concepto histórico aglutinaría en un imaginario "ancestral"

Yo creo que el quechua es otra forma de rescatar nuestras culturas ancestrales, rescatar digamos aspectos colectivos que van, tanto desde el lenguaje como en las formas de organización social, y también rescatar todas las experiencias de la vida campesina (Pepe 1.6.04).

Razón pragmática / instrumental: lograr comunicarse en el campo y la ciudad

El argumento más común para favorecer la enseñanza del quechua en el colegio es la necesidad que los profesionales tendrían de la lengua en su desempeño en el área rural. Jimena, ingeniera química-ambiental, habla de experiencia propia:

En mi carrera profesional he tenido muchos problemas digamos por no hablar quechua, el hecho. Por ejemplo, cuando hacía mi investigación en el Norte de Potosí y tratar con campesinos, en muchos casos con gente que no hablaba el español y otro que tenía que capacitar en todo lo que es manejo de aguas. Entonces, tenía que llevar gente, o sea, compañeros míos de la Universidad que hablan quechua para que ellos hicieran la capacitación por mí, cosa que yo debería hacer. Ahí digamos, la necesidad, antes yo no le había dado la importancia al quechua, pero ahí dije que sí deberíamos tener un conocimiento... en ningún momento he estado pensando que la gente con la que voy a trabajar era del campo que probablemente no hable español, o sea todos (Jimena 27.6.04). 
La formación universitaria en disciplinas de ingeniería (carreras de tecnología) no prepara a los estudiantes para enfrentar la realidad lingüística y cultural de la región quechuahablante. Estudiantes con dominio del quechua empezaron a ser buscados como traductores y ejecutores de capacitaciones en quechua construyéndose la noción de un capital económico. Esto es, al parecer, transmitido por los propios padres a sus hijos:

Eso justamente yo te iba a decir, yo tengo un sobrino que ha salido ingeniero civil aquí en San Simón y él es hidráulico. Entonces, después de terminar su carrera, ha pasado clases de quechua porque tiene que ir al campo. Entonces, yo le digo hija, en este momento lo rural, cualquier trabajo que se tenga que desarrollar, a veces se tiene que ir al campo y tú tienes que comunicarte con la gente de allá, es un idioma nuestro, a mí me parece importante que aprendas no? (Petra 23.6.04)

Saber quechua es una herramienta laboral para esta madre de familia econometrista, específicamente para el desempeño "en el campo". En la última parte del testimonio aparece una referencia sobre la distancia geográfica que incluye, sin lugar a dudas, lo social, "gente de allá". La distancia se superaría con una lengua que es patrimonio común (boliviano?) y no solamente de los pobladores rurales.

El abogado Ariel puede dar un buen ejemplo de estos encuentros asimétricos, en los cuales la estrategia no consiste solamente en "saber quechua" sino en "saber hablar quechua":

Antes yo le puedo señalar que la participación popular no nos permitía hablar o no les permitían a los originarios hablar. La participación popular ha permitido mayor participación de ellos, mayor toma de decisiones y por tanto como profesionales a veces en las consultas de los CPP (Consejeros de Participación Popular) tenemos que dialogar directamente. Le digo con honestidad, aquellos profesional que hablan quechua tienen mayor ventaja, yo he visto eso de saber hablar quechua. Había una ingeniera agrónoma que trabajaba conmigo y que tenía que llevarla a todas las señoras obligatoriamente, porque hablaba tan dulce el quechua, con tanta facilidad, con tanta elasticidad que yo hablaba y era pues un tartamudo. Es decir, entonces, le digo, esos profesionales tienen ventaja (Ariel 29.6.04).

El abogado Ariel distingue entre las profesiones que exigen el dominio del quechua y "aquellas que se libran un poco".

$Y$ el requisito que se necesita en algunos trabajos de este tipo, es indispensable el conocimiento del quechua, fundamentalmente en la profesión ésta, en agronomía, sea en ingeniería civil, sea médico, sea sociólogo, sea abogacía, aunque los economistas y auditores se libran un poco porque ellos están más enmarcados en libros. Pero en las 
demás carreras incluyendo los que trabajan en provincia o cuando viene cualquier paciente de provincia y habla en quechua... (Ariel 29.6.05)

Profesionales que focalizan en objetos como números o cifras y no implican comunicación o relacionamiento con personas estarían "absueltos" del quechua. Por lo demás, e independientemente de que se trate del ámbito rural o urbano, la necesidad del quechua en el desempeño de la profesión está dada por la movilidad geográfica y económica de los sujetos "con quienes uno tiene que relacionarse".

Al ubicarnos en el contexto cochabambino, encontramos que hay una necesidad, incluso social, de que los profesionales de Cochabamba tengan su conocimiento de quechua. Si usted ve en la antesala, hay un campesino que está esperando, como me ha esperado una señora de clase media y como tengo que relacionarme con él, necesariamente tengo que hablar el quechua. En el caso mío que soy abogado también que tengo necesidad de resolver los problemas, me tengo que interrelacionar con esta gente (Ariel 29.6.05).

Bajo "necesidad social" Ariel se refiere también como arriba al aspecto relacional de la comunicación, rescatando, sin embargo, la "resolución de problemas" antes que el convencimiento de unos sobre otros. En este caso, se trata de una relación menos asimétrica entre el cliente que cuenta con los recursos para pagar la atención que recibe del profesional y la dependencia económica que esto implica para el último. No está, sin embargo, ausente la tipificación del cliente con la cual se establece una diferencia social entre él o ella y el profesional. Ariel da un ejemplo de "esta gente", cliente monolingüe quechua que vive en la ciudad.

Yo tengo una cliente que no habla ni una gota de español, ni una palabra de español y ella vive en la ciudad. Tiene su casa, y tiene una casa tan hermosa, muy bonita que han comprado, tiene lavaplatos en su cocina pero los lava en el suelo. Verdad, hemos ido con mi esposa, tiene los lava platos pero lava en el suelo en un bañador y le hemos mostrado qué es un lavaplatos pero no entiende (Ariel 29.6.05).

Monolingüismo en lengua indígena, visibles recursos económicos y permanencia en la ciudad es una combinación de características que desafía el estereotipo social así como el estereotipo de cliente de abogado:

Y ésta es una cliente que sólo habla en quechua, algunas palabras habla, yo le entiendo, pero cuando yo quiero hablarle, me entiende la mitad, hacemos esfuerzo de entendernos. A veces está aquí en las tardes porque toda su situación de tierras, terrenos... es una señora que tiene mucha economía pero no tiene comunicación española. Le veo los impuestos, le veo las casas, le veo todo (Ariel 29.6.05). 
La presencia del quechua en la ciudad es una realidad, aunque para algunos padres de familia esto se evidencie solamente en situaciones puntuales, anecdóticas. De todos modos, como se puede ver en el siguiente testimonio, antes que negar los cambios de expansión geográfica de lenguas, se buscan formas de responder a ellos. Lalo, piloto del Lloyd Aéreo Boliviano cuenta el 27.6.04:

Lalo: Yo pienso que todos deberían saber porque es una lengua que, querramos o no querramos, estamos relacionados con él y necesitamos en ciertos momentos, claro, aunque unos más y otros menos, pero en algún momento lo usamos.

He necesitado la ayuda, en un caso muy interesante, teníamos un vuelo de Cochabamba a Sucre cuando vemos abordar a 50 niños que eran del campo y ninguno hablaba castellano, Entonces, por regulación cuando se hace la demostración de uso de equipo de emergencia, el pasajero tiene que saber lo que se está diciendo, entonces vimos la dificultad de..., alguien tenía que hacer el trabajo para que la gente entienda lo que tenía que hacer, entonces nos pusieron en dificultades y entonces tuvimos que buscar una persona que lo haga.

I: De los pasajeros o de los tripulantes?

Lalo: No, no fue pasajero, llamamos, empezamos a investigar a ver quién habla, lo sacaron de una oficina y vino y les explicó, tuvo que ir hasta Sucre y volvió con nosotros.

I: ¿Ah si?

$\mathrm{Si}$, pero cumplimos no? Y esa ha sido una anécdota no?

Podemos concluir esta parte diciendo que la razón práctica-pragmática es para los adultos la más fuerte cuando se trata de justificar el beneficio de la asignatura quechua. Esto justificaría la implementación de un modelo discursivo de educación intercultural que busca "educar para interactuar" (Dietz, 2003, p.165). Este modelo; "centrado en generar experiencias de interculturalidad vividas de forma conjunta por los educandos" (op.cit., p.166) parte del ámbito escolar como foco de actuación, tematiza la heterogeneidad existente en el aula y la aprovecha como generadora de mecanismos intragrupales de formulación, negociación y resolución de conflictos. En tanto está dirigido a la sociedad en su conjunto y no se restringe a los sectores minorizados (indígenas), el modelo para interactuar respondería de modo más cercano a la necesidad de diálogo expresada por la defensora del pueblo en la parte introductoria de este trabajo. Un requisito para que este modelo aporte a la construcción de una sociedad intercultural es, de acuerdo a Díaz-Aguado \& Andrés Martín ${ }^{11}$ citado en Dietz (op.cit., p.166), transformar el proceso de construcción de los conocimientos y las normas que definen la cultura 
escolar. El alumno recibiría en esta transformación un papel activo en la construcción de conocimientos, la mirada positiva hacia sus dudas y las experiencias de heterogeneidad. El método tradicional centrado en la actividad del profesor debe ceder en este modelo a un método centrado en el alumno como responsable de su propio aprendizaje.

Por otro lado, al igual que sus hijos, los padres y madres rescatan el argumento de generar un sentido de identidad nacional, con tintes patrióticos más fuertes entre los adultos y con sentimiento de lo originario entre los niños. Se evidencian las expectativas de los padres y alumnos respecto a la enseñanza de la lengua indígena de comprobada vitalidad en ámbito urbano para contribuir a la construcción de "lo nuestro" en una época marcada por constantes y notorios movimientos contrahegemónicos protagonizados por organizaciones indígenas y populares.

Es de destacar, finalmente, la presencia del argumento político, la expresión más clara de la demanda de un modelo discursivo de educación intercultural de transformación. Este modelo rescata según Dietz (2003, p.164-165) la pedagogía crítica en un ejercicio de "de-construcción de las excluyentes y opresivas identidades de la mayoría" (ibidem), pretendiendo abarcar con el cambio societal a instituciones y ámbitos extra-escolares.

\section{Conclusion}

Para los niños y adultos, la lengua indígena no se restringe a su sentido pedagógico sino se vuelve un "recurso" desde el punto de vista de planificación lingüística, es decir, una herramienta social. Más allá del conocimiento de la lengua indígena, el uso del quechua es visto por este grupo de actores como una "ganancia" en el sentido pragmático, un beneficio en el sentido cognitivo y afectivo y un aporte a la necesaria interculturalización de los alumnos.

Es notoria la contradicción entre una ideología progresista expresada por los padres de familia que favorecería la interculturalización del alumnado (DESEO) y la práctica de enseñanza de quechua que responde a la cultura escolar (REALIDAD), cuyo fin es su propia reproducción antes que la formación hacia la interculturalidad.

Como agua y aceite, así se separan la realidad del aula y las expectativas de los usuarios del colegio respecto a la enseñanza de una lengua indígena de tradición oral, de comprobada vitalidad en ámbito urbano en un país y época marcados por constantes y notorios 
movimientos contrahegemónicos protagonizados por organizaciones indígenas y populares. Encontramos muchos elementos que nos remiten a la percepción que las madres y padres de familia tienen sobre el tratamiento del quechua en el colegio. Sin duda, sacar la lengua indígena del ámbito doméstico donde vive (en cierta manera también en hogares monolingües castellanos!) e ingresarla al ámbito escolar para estudiarla es un paso político importantísimo y a todas luces necesario para su reconocimiento y valoración en la sociedad, como los padres y alumnos mismos también sostienen. Sin embargo, el análisis de los datos recogidos en la investigación revela que avanzaríamos en la interculturalización de los alumnos escuchándolos, averiguando de ellos y sus padres qué desean, piensan, recuperando su saber y sentido común surgidos de la vida cotidiana misma.

La importancia de esta asignatura en colegios particulares que forman a las élites del país es innegable, sin embargo, no parece haber sido reconocida por los colegios o, en todo caso, no se plasma en el aula. Debemos reconocer como válida la lapidaria afirmación de (Velasco y otros 1993, p.319).

Asentada, quizás como ninguna otra institución contemporánea, en la creencia de que la sociedad es capaz de construirse y transformarse conscientemente a sí misma, la escuela no puede negar su contribución real a la conservación de las estructuras sociales, políticas y económicas que en apariencia desea transformar.

Quién sabe desescolarizando el quechua, despojándolo de la envoltura de la cultura escolar, rescatándolo de una pedagogía de lengua extranjera y poniéndolo a disposición de una propuesta pedagógica como la construida por los interesados logremos nuevos y más hablantes y amantes de la lengua. Quién sabe aportemos de esta forma a la valoración de la lengua, de sus hablantes y de la cultura quechua, colocando el tratamiento escolar de la lengua indígena al nivel que ésta se merece por justicia política. Quién sabe desde una distinta asignatura del quechua podríamos llegar a fortalecer entre los alumnos de este sector de la sociedad cochabambina y nacional el sentimiento de 'lo nuestro' en una sociedad intercultural.

\section{Notas}

${ }^{1}$ El Censo de 2001 estableció 8'274,325 habitantes en el territorio boliviano de aprox. 1 millón de $\mathrm{Km} 2$.

${ }^{2}$ En el último lustro, las convulsiones sociales en el país (abril 2001, febrero y 
octubre 2003 y junio 2005, entre las más destacadas) tuvieron escenarios urbanos de las regiones de valle y altiplánica, en especial en Cochabamba, La Paz y El Alto. ${ }^{3}$ En Cochabamba, específicamente, se encontró que, en 2001, un $10 \%$ de establecimientos particulares tenían algún tratamiento curricular de quechua en la primaria (Sichra, 2001).

${ }^{4}$ El total de habitantes de Cercado, como se denomina al municipio de Cochabamba, según el último censo fue de 570,000.

${ }^{5}$ Se trata de cursos del último ciclo de la primaria de los colegios San Agustín y CENDI. Los niños entre 10 y 12 años pertenecen a familias de profesionales independientes como ser médicos, abogados, arquitectos, ingenieros, economistas, psicólogos, antropólogos, pilotos, docentes universitarios y también funcionarios gubernamentales en los gobiernos pasados. Agradezco la disposición de los directores y las docentes de ambos establecimientos de abrirme sus aulas sin contemplaciones, y la generosidad de madres, padres y alumnos de brindarme su tiempo y su interés.

${ }^{6}$ Como se ha difundido hace unos días, al inicio del año escolar 2006/07, en Alemania y en Austria se da el caso de aulas íntegras de primaria conformadas por niños de familias migrantes de hasta 22 lenguas diferentes y con incipiente dominio del alemán.

${ }^{7}$ Hasta el mejor de los maestros no puede proteger completamente a sus alumnos de ello. Inevitablemente, este currículo oculto de la escuela añade prejuicio y culpa a la discriminación que una sociedad practica contra algunos de sus miembros y comprende el privilegio que tienen como una nueva condescendencia hacia la mayoría (traducción da autora).

${ }^{8}$ El Colegio San Agustín fue fundado por los Padres Agustinos de Holanda en 1954 como colegio secundario industrial. Desde 1969 incluye en su oferta el último ciclo de primaria. Los niños provenientes de colegios particulares y fiscales ingresan al colegio en sexto de primaria previo examen de competencia. Por medio de un examen de admisión, el San Agustín recibe cada año a 90 alumnos de colegios fiscales y particulares, otorgando becas a familias que las necesiten. El colegio mantiene una imagen de ser selectivo por aptitud y no por origen. Por otro lado, también cultiva la fama de graduar en cuarto de secundaria solamente a un tercio de los alumnos que ingresaron siete años atrás al colegio, hecho relacionado con la exigencia de estudio y el énfasis en las asignaturas consideradas como ciencias exactas (matemática, física, química). Desde 1992, la propiedad, gestión y administración del colegio es de la Fundación Educacional San Agustín.

${ }^{9}$ El colegio CENDI (Centro de Desarrollo Integral) se crea en el año 1987 como unidad educativa de la Federación de Docentes de la Universidad Mayor de San Simón (UMSS). Tres años después es incorporado a la Facultad de Humanidades de esa Universidad.

${ }^{10}$ SAVILLE-TROIKE, M. 1976, Foundations for Teaching ESL, Englewood Cliffs, Nueva Jersey: Prentice Hall.

${ }^{11}$ DÍAZ-AGUADO, M.J. y M.T. Andrés Martín 1999, “La integración escolar de los inmigrantes desde una perspectiva intercultural" OFRIM Suplementos noviembrediciembre. p.65-82. 


\section{Referências}

ALBÓ, Xavier y ROMERO, Ruperto. 2004. “M5 Interculturalidad" Módulo 5 del Programa de Formación e Innovación Institucional y Académica dirigido a los Institutos Normales Superiores públicos de Bolivia. La Paz. (Mimeo)

BERTELY, María. Conociendo nuestras escuelas. México D.F.: Paidos, 2000.

BODNAR, Yolanda y RODRÍGUEZ, Elsa. Etnoeducación y diversidad cultural. In: . Urdimbres y tramas culturales. Bogotá: Corprodic, 1993, p.23-44.

CRAWFORD, Alan y CADENAS, Herminia. Métodos comunicativos para la adquisición de una segunda lengua. In: JUNG, Ingrid y LÓPEZ, Luis Enrique (comps.) Abriendo la escuela. Lingüística aplicada a la enseñanza de lenguas. Madrid: PROEIB Andes/Inwent/Morata, 2003, p. 227-247.

DIETZ, Günther. Multiculturalismo, Interculturalidad y Educación:Una aproximación antropológica. Granada: Universidad de Granada. 2003.

GIGANTE, Elba, LEWIN, Pedro ; VARESE, Stefano. 1986. Condiciones etno-lingúísticas y pedagógicas para una educación indígena culturalmente apropiada. Ponencia presentada en el Seminario Taller Elaboración de currículo intercultural y preparación de material didáctico para la enseñanza en y de lengua materna (UNESCO/OREALC) en octubre de 1986 en Buenos Aires.

HUTMACHER, Walo. Education systems, social integration and inequality. IN: TAWIL, S. (ed) Curriculum Change and Social Inclusion: Perspectives from the Baltic and Scandinavian Countries. Final Report of the Regional Seminar Vilnius, Lithuania, 5-8.XII. 2001. Accesible en la página: http:/ / www.ibe.unesco.org/Regional/baltic_sea/Balticpdf/vilnius4e.pdf. Consulta junio 2005.

ILLICH, Ivan. Deschooling society. New York: Harper and Row, 1970. Accesible en la página: $w w w$.preservenet.com/theory/Illich/Deschooling/intro.html. Consulta junio 2005.

INE. Instituto Nacional de Estadística. Bolivia: Características de la Población Censo 2001. Serie I Resultados Nacionales Vol. 4. La Paz: INE, 2002.

MECs. Ministerio de Educación y Culturas MECs. Nueva Ley de la Educación Boliviana «Avelino Siñani y Elizardo Pérez ». Anteproyecto de Ley. La Paz : MECs, 2006.

PERRENOUD, Philippe. La fabrication de l'excellence scolaire. Ginebra:Droz, 1984.

PROEIB Andes. Investigación regional: Logros y retos de la Educación Intercultural para Todos en Bolivia. PROEIB Andes: Cochabamba, 2005. [Mimeo]

ROMERO DE CAMPERO, Ana María. Está por nacer otro país. Revista ¡OH! 19.6.2005. Cochabamba.

SICHRA, Inge. ¿Para qué me enseñan quechua! ¿Acaso voy a ser dirigente campesino? La enseñanza del quechua en colegios de la ciudad de Cochabamba, Bolivia. PROEIB Andes, 2001.[mimeo]

. Enseñanza de lengua indígena e interculturalidad: ¿entre la realidad y el deseo? Investigación sobre la enseñanza del quechua en dos colegios particulares en Cochabamba. Informe de investigación 1. Cochabamba: PROEIB Andes, 2006. 
SILVA-CORVALÁN, Carmen. La adquisición de lenguas: Una revisión de la literatura con especial referencia al castellano. In: JUNG, Ingrid y LÓPEZ, Luis Enrique (comps.) Abriendo la escuela. Lingüística aplicada a la enseñanza de lenguas. Ma d rid: PROEIB Andes/Inwent/Morata, 2003, p.24-38.

VELASCO, Honorio; GARCÍA, Javier; DÍAZ DE RADA, Angel. Introducción a Educación y escuela como procesos socioculturales. In: VELASCO, Honorio et al. (eds) Lecturas de antropología para educadores. Madrid:Trotta, 1993, p.315-324.

WALSH, Catherine. La interculturalidad en la Educación. Lima: DINEBI, 2001.

WODAK, Ruth. De qué trata el análisis crítico del discurso (ACD). Resumen de su historia, sus conceptos fundamentales y sus desarrollos. In: WODAK, Ruth y MEYER, Michael (Eds.). Métodos de análisis crítico del discurso. Barcelona: Gedisa, 2003, p.17-34.

Recebido em 02 de agosto de 2006.

Aprovado para publicação em 30 de agosto de 2006. 